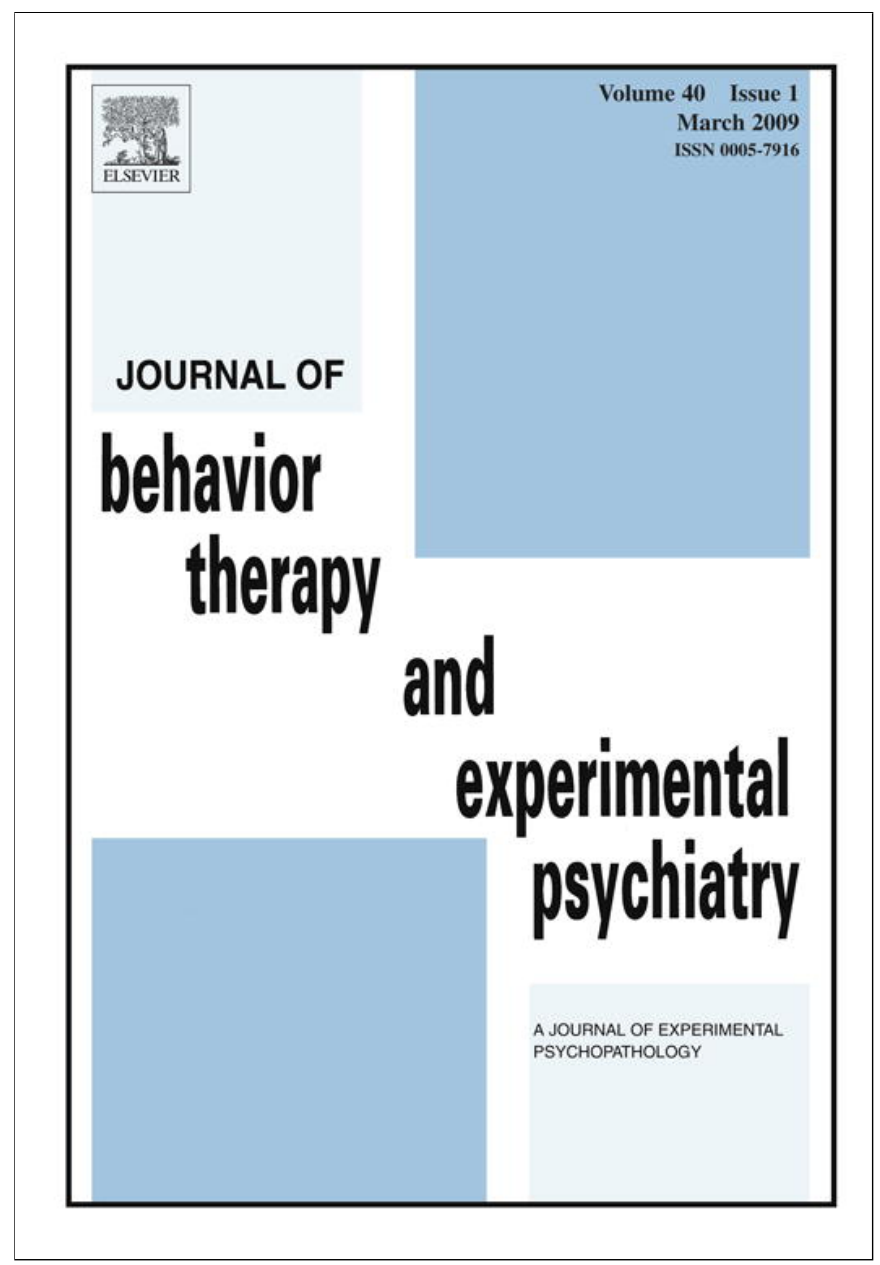

This article appeared in a journal published by Elsevier. The attached copy is furnished to the author for internal non-commercial research and education use, including for instruction at the authors institution and sharing with colleagues.

Other uses, including reproduction and distribution, or selling or licensing copies, or posting to personal, institutional or third party websites are prohibited.

In most cases authors are permitted to post their version of the article (e.g. in Word or Tex form) to their personal website or institutional repository. Authors requiring further information regarding Elsevier's archiving and manuscript policies are encouraged to visit:

http://www.elsevier.com/copyright 


\title{
Reducing cognitive vulnerability to depression: A preliminary investigation of MEmory Specificity Training (MEST) in inpatients with depressive symptomatology
}

\author{
Filip Raes ${ }^{a, *}$, J. Mark G. Williams ${ }^{b}$, Dirk Hermans ${ }^{a}$ \\ ${ }^{a}$ Department of Psychology, University of Leuven, Tiensestraat 102, 3000 Leuven, Belgium \\ ${ }^{\mathrm{b}}$ Department of Psychiatry, University of Oxford, UK
}

Received 26 November 2007; received in revised form 4 February 2008; accepted 4 March 2008

\begin{abstract}
Reduced specificity of autobiographical memory retrieval represents an enduring vulnerability factor for depression. The present study is a preliminary evaluation of a newly developed group-based intervention program to increase specificity of memory retrieval. The MEmory Specificity Training (MEST) was administered on a weekly basis for 4 consecutive weeks to 10 inpatients with depressive symptomatology. Whereas earlier studies found that memory specificity does not improve following treatment as usual, the present results showed that participants' retrieval style became significantly more specific following MEST. These results suggest that the MEST may offer a potential and promising intervention to tackle a core cognitive process involved in depression and depressive vulnerability.

(c) 2008 Elsevier Ltd. All rights reserved.
\end{abstract}

Keywords: Depression; Autobiographical memory; Training

\section{Introduction}

A large body of evidence indicates that depressed individuals find it difficult to retrieve specific personal events from their memory as compared to normal controls (for a review, see Williams et al., 2007). For example, when asked to recall a specific memory in response

\footnotetext{
* Corresponding author. Tel.: +32 163258 92; fax: +32 16326099 .

E-mail address: filip.raes@psy.kuleuven.be (F. Raes).
} 
to a cue-word, depressed people respond more often than non-depressed controls with overgeneral memories rather than with the requested specific memories. The latter refer to personal events that happened on a particular day (e.g., 'Tuesday last month, when I went running in the forest and was attacked by a buzzard'), whereas the former summarize memories of the same type without the specification of a single particular occasion (e.g., 'the times I go running in the forest'). This repeated observation has been labelled 'overgeneral memory' or 'reduced autobiographical memory specificity' (Williams et al., 2007).

Interestingly, this reduction in specificity for personal memories is not just a concomitant of a depressed mood state. Several studies have shown that when patients are recovered or in remission from their depression, their memory specificity does not improve (e.g., Brittlebank, Scott, Williams, \& Ferrier, 1993; Raes, Hermans, Williams, Beyers, et al., 2006). Likewise, formerly depressed individuals are equally impaired in their retrieval of specific memories as currently depressed patients, and both these groups are clearly less specific with respect to their memory retrieval as compared to never depressed controls (e.g., Mackinger, Pachinger, Leibetseder, \& Fartacek, 2000; Park, Goodyer, \& Teasdale, 2002; Williams \& Dritschel, 1988). Moreover, studies also show that this phenomenon of reduced memory specificity has predictive value for the course of depression: The greater the extent to which people are characterized by reduced specificity for memories, the slower their recovery is (e.g., Brittlebank et al., 1993; Hermans et al., in press; Peeters, Wessel, Merckelbach, \& Boon-Vermeeren, 2002; Raes, Hermans, Williams, Beyers, et al., 2006). And even in non-clinical groups or populations that are not suffering from clinically significant pathology, reduced memory specificity predicts increased emotional (depressed) reactivity, for example, to stressful life-events (e.g., Bryant, Sutherland, \& Guthrie, 2007; Gibbs \& Rude, 2004; Mackinger, Loschin, \& Leibetseder, 2000; Van Minnen, Wessel, Verhaak, \& Smeenk, 2005; for a review, see Raes, Hermans, Williams, \& Eelen, 2007).

At least four potential routes have been proposed via which reduced memory specificity leads, or is linked to depression. A first way through which reduced memory specificity negatively affects depression is that it hinders effective social or interpersonal problem solving. Research has demonstrated such association between reduced memory specificity and less effective problem solving. Using the Means-Ends Problem-Solving procedure (MEPS; Platt \& Spivack, 1975), a task in which respondents are asked to generate solutions to hypothetical social problem situations, studies have shown that (a) the less specific depressed patients are in their memory retrieval, the less effective the solutions are they generate to such MEPS scenario's (e.g., Evans, Williams, O’Loughlin, \& Howells, 1992; Goddard, Dritschel, \& Burton, 1996, 1997; Raes et al., 2005), that (b) manipulation of memory specificity changes problem-solving performance (Williams et al., 2006) and that (c) memory specificity moderates the effect of negative mood on problem-solving performance (Williams, Barnhofer, Crane, \& Beck, 2005). The idea is that an unspecific memory base is not very helpful to a person when generating strategies for solving interpersonal problems (e.g., Evans et al., 1992). Poor problem-solving capacities in turn might lead to depressed feelings or further worsen current depression because it inevitably leads to (more) negative social encounters, and further decreases the chances for positive social reinforcement (Hermans, Raes, \& Eelen, 2005).

Another, second way in which lack of memory specificity might contribute to the maintenance of depression or vulnerability for relapse is that it may increase feelings of hopelessness through its impact on imageability of the future, that is, the ability to imagine specific images of the future. Williams et al. (1996) showed that the induction of a less specific retrieval style reduces the specificity of images of one's personal future (see also de Decker, 2001). The link 
between feelings of hopelessness in depressed patients and an unspecific and vague view on one's future is self-evident. The idea, thus, is that memory specificity, via its negative effect on the specificity level of the image of one's own future, fuels feelings of hopelessness, and thereby installs or further exacerbates depressed feelings.

A third way in which reduced memory specificity may render people vulnerable for depression or impede recovery from it, is through a spiraling, reciprocal relationship with depressive rumination (Williams, 1996, 2004; Williams et al., 2007). Rumination could be broadly defined as repetitive and unhelpful thinking about one's own depressed or sad feelings and about related problems or past issues. Both correlational and experimental studies have provided evidence for the idea that reduced specificity in the retrieval of memories and ruminative thinking are mutually reinforcing one another, further exacerbating depressed feelings (e.g., Park et al., 2002; Raes, Hermans, Williams, Beyers, et al., 2006; Raes, Hermans, Williams, Geypen, \& Eelen, 2006; Ramponi, Barnard, \& Nimmo-Smith, 2004; Watkins \& Teasdale, 2001, 2004; Watkins, Teasdale, \& Williams, 2000).

A fourth way in which reduced memory specificity might lead to (more) depression, pertains to the relative lack of experiential exposure to negative memories and the attached negative emotions (see Hermans et al., 2005). Exposure to distressing memories and feelings, although disturbing and unpleasant in the short-run, is associated with long-term benefits to psychological well-being (e.g., Littrell, 1998; Pennebaker \& Seagal, 1999). This naturally occurring exposure effect, then, might be relatively absent in individuals who tend to recall past events in a less specific form, in that they might be avoiding necessary exposure that way ('experiential avoidance'; Hayes, Wilson, Gifford, Follette, \& Strosahl, 1996). In the short-run, this experiential avoidance (or lack of exposure) might be advantageous. In the long-term, however, this may proof disadvantageous and put people at risk for developing or exacerbating emotional problems, for example, depression (see e.g., Hayes et al., 1996; see also Golden, Dalgleish, \& Mackintosh, 2007).

Previous research in the domain of reduced autobiographical memory specificity (and depression) has mainly focused on the study of the correlates and mechanisms of this vulnerability factor (Williams et al., 2007, for a review). However, it goes without saying that the accumulated body of knowledge in this domain could provide an important input to clinical interventions, in particular for depression. For example, based on the above described state of the art, it seems reasonable to assume that the remediation or reduction of overgeneral memory retrieval may be an important therapeutic target. Notwithstanding the fact that the existing literature clearly underscores the (clinical) importance of reduced memory specificity, this evident translation into clinical interventions has hitherto been insufficiently explored. Our current study is precisely an attempt to start filling this lacuna.

The primary aim of the study is to explore the feasibility of a newly developed group-based intervention program to increase memory specificity. More particularly, our aims are (a) to explore whether memory specificity can be increased in patients with depressive symptomatology (that is, remediation of the targeted depressogenic vulnerability factor, i.e. reduced memory specificity) and (b) to examine whether the observed gains in memory specificity are accompanied by improvements in other key variables, like rumination and problem-solving performance, that are assumed to mediate the impact of memory specificity on the course of depressive symptoms (see our review above).

As mentioned, memory specificity does not typically improve in depressed patients when offered treatment as usual (e.g., Brittlebank et al., 1993; Raes, Hermans, Williams, Beyers, et al., 2006). Broader therapeutic programs, such as Mindfulness-Based Cognitive Therapy 
(Williams, Teasdale, Segal, \& Soulsby, 2000) or standard cognitive behavior therapy for depression (McBride, Segal, Kennedy, \& Gemar, 2007) have, however, been found to increase memory specificity.

Only one study so far has explored to what extent overgeneral memory retrieval can be remediated using a directly targeted intervention, specifically aimed at increasing memory specificity. Serrano, Latorre, Gatz, and Montanes (2004) offered a newly developed life review therapy to 20 older adults (aged 65-93) with clinically significant depressive symptoms. The life review intervention was individually administered on a weekly basis for 4 consecutive weeks. The main focus was on assisting the elderly in the retrieval of specific, albeit exclusively positive, memories. Each week the retrieval practice focused on a particular life period (childhood, adolescence, adulthood, and summary) for which participants were prompted to recall specific positive recollections by a set of 14 questions (e.g., "What is the most pleasant situation that you remember from your childhood?", "Tell me a time that you remember experiencing the most pride at work"). It was observed that, relative to a control group $(n=23)$, the participants that received the intervention showed fewer depressive symptoms, less hopelessness and improved satisfaction at post-test (i.e. 2 weeks after the last intervention session). Further analyses showed that the experimental group, compared to controls, became more specific in their retrieval of positive and neutral memories, but not for negative memories. Participants who increased the most in generating specific memories were also found to improve most with respect to depressive symptoms, hopelessness, and life satisfaction. A major restriction of this study and its intervention is, however, that it exclusively focused on the retrieval of positive episodes or memories. Hence, the possibility that the observed beneficial effects were due to this focus on pleasant events cannot be ruled out. Indeed, as mentioned, patients did not improve in their retrieval of specific negative memories. This makes it difficult to reliably interpret the observed effects as being caused - in terms of underlying processes - by improvements in specificity of memory retrieval per se. Besides this important methodological concern, the exclusion of working with negative material does not really fit well with theories in the field of reduced autobiographical memory specificity, which primarily focus on the cognitive-emotional processing of negative autobiographical memories.

In order to address these and other shortcomings in the program of Serrano et al. (2004), we developed a new group-based intervention program, specifically targeted at the improvement of specificity of memory retrieval for both positive and negative materials. Additionally, the program integrates some of the most recent findings from experimental psychopathological research that are of relevance for the issue of memory specificity (e.g., Moberly \& Watkins, 2006; Neumann \& Philippot, 2007; Watkins \& Moulds, 2005).

Our intervention is not framed in, or does not form part of a larger therapeutic program (like, for example, life review therapy, MBCT, or standard CBT). Rather, it represents a stand-alone intervention specifically aimed at increasing specificity of memory retrieval. As such, our intervention nicely fits with Barlow's (2004) recent plea that psychological interventions should preferentially be tailored to target pathological processes, as identified in (experimental) psychopathological research. Furthermore, the fact that we focus on a factor of which research clearly shows that it is implicated in the maintenance of depressive symptoms (Williams et al., 2007) is in line with Barlow's recommendation that new interventions should primarily focus on the prevention of recurrence of future depressive episodes.

To summarize then, the present study is designed as a preliminary evaluation of a newly developed group-based intervention program to reduce overgenerality of memory retrieval. The study's first aim is to see whether this program indeed reduces this known vulnerability 
factor, in that it increases patients' specificity of memory retrieval. Second, we will examine to what extent the observed improvements in memory specificity are accompanied by improvements in variables that are assumed to mediate the impact of memory specificity on the course of depressive symptoms (reduction of ruminative thinking, feelings of hopelessness, and experiential avoidance; and increase in problem-solving skills). Our prediction here is that participants who increase the most in the production of specific memories will improve most on these other variables. Thus, in the present pilot study, we will focus on the short-term effects of the memory training on these mediating variables. Possible longer-term effects on the course of depressive symptoms, established via changes in the mediating variables, are not examined in the present pilot study, which does not include longer-term follow-up (see Section 4). Third, we will examine whether improvements in memory specificity also generalize to improvements on other tasks than the standard AMT cue-word task. Fourth, we will check to what extent improvements in, for example, memory specificity, are not simply due to a decrease in depressive complaints.

We used patients experiencing significant current depressive symptomatology as participants in the current training study, since prior work shows that (a) this population suffers from reduced memory specificity and that (b) the extent to which such patients are characterized by reduced specificity for memories predicts slower recovery from their depression (see above).

\section{Method}

\subsection{Participants}

Participants were 10 female inpatients, aged 32-55 $(M=47.40 ; \mathrm{SD}=7.56)$, all experiencing significant depressive symptomatology as confirmed by the team's psychiatrist and psychologist (KLINA, Brasschaat: $n=6$; Sint-Norbertushuis, Duffel: $n=4$ ). Eight of them fulfilled DSM-IV criteria for a major depressive episode at the start of the study, as indicated by their scores on the Major Depression Questionnaire (MDQ; see Section 2.2). The mean score on the BDI-II $(M=25.30 ; \mathrm{SD}=10.70)$ indicates that this group is suffering from significant (or moderately severe) levels of depressive symptoms. Seven more patients (five men) had started the training program, but were not retained for analyses. One patient did attend the four sessions, but did not fill out pre- and post-AMT and SCEPT. Four patients left the hospital before Session 3. Two patients decided to end their participation prematurely because they experienced the exercises as 'emotionally too difficult'. Both these patients had very recently experienced personal (traumatic) losses, which possibly suggests that recent traumatic experiences may be a contra-indication for this memory specificity training.

\subsection{Measures}

\subsubsection{The Major Depression Questionnaire (MDQ; Van der Does, Barnhofer, \& Williams,} 2003)

The MDQ is a self-report questionnaire which measures the presence of past and current depressions. It consists of a series of questions that cover all DSM-IV criteria for past and current major depression (APA, 1994). The MDQ has shown high consistency with diagnoses based on SCID interviews (see Williams, Van der Does, Barnhofer, Crane, \& Segal, 2008). 


\subsubsection{Autobiographical Memory Test (AMT; Williams \& Broadbent, 1986)}

The AMT measures memory specificity. For each of 10 cue-words (five positive and five negative, presented in alternating order), participants have to write down a specific memory that the cue-word reminds them of. It is stated in the instructions that a specific memory refers to one particular occasion or event that happened on a particular day at least 1 week before. Each response is coded as either specific (i.e. a memory for an event lasting a day or less and which occurred at a certain place and time), overgeneral categoric (i.e. a memory for a repeated event without specification of a particular time), extended (i.e. a memory referring to an extended time period that lasted longer than a day), semantic association (i.e. a mere verbal association to the cue rather than a memory), or omission. Using this scoring procedure, previous studies that were conducted at our lab obtained good reliability (Raes, Hermans, de Decker, Eelen, \& Williams, 2003; Raes, Pousset, \& Hermans, 2004) with interrater agreement ranging from $92 \%$ to $99 \%(K=0.83-0.96)$, comparable with previous studies of other research groups. Two parallel sets of 10 cue-words were used. Both sets of cues are matched for imageability, familiarity, and emotional extremity.

\subsubsection{The Sentence Completion for Events from the Past Test (SCEPT; Raes, Hermans, Williams, \& Eelen, 2007)}

The SCEPT comprises 11 sentence stems probing for past experiences. A sample item is "I still remember well how...". Participants are instructed to provide continuations to these incomplete sentences. Afterwards, sentence completions are coded by the experimenter, using the following coding categories: semantic associate (referring to personal overgeneral semantic information; e.g., "...I used to be a very shy girl"), categoric memory (referring to a category of similar, repeated events; e.g., "...my grandmother used to play games with me when I was little"), extended memory (referring to an extended period of time; e.g., "...my time in junior high"), specific memory (referring to a specific personal past experience that did not last longer than a day; e.g., "...I was sad the day my grandfather died"), and omission. Good interrater agreement was shown $(87 \%, K=0.82$; Raes et al., 2007). The SCEPT was administered to examine to what extent improvements in memory specificity would also generalize to a task that does not ask respondents to recall specific memories in response to cue-words (cf. the training materials and the standard AMT cue-word procedure).

\subsubsection{Beck Depression Inventory (BDI-II; Beck, Steer, \& Brown, 1996)}

The BDI-II is a widely used self-rating measure to assess severity of depressive symptoms and consists of 21 four-choice statements (range $=0-63$ ). Participants are asked to mark the statements that best describe how they felt during the past 2 weeks. The Dutch version by Van der Does (2002) is used.

\subsubsection{The Leuven Adaptation of the Rumination on Sadness Scale (LARSS; Raes, Hermans, Williams, Bijttebier, \& Eelen, 2007)}

The LARSS is a 17-item self-report questionnaire measuring rumination on sadness. Items are rated on a 5-point scale (not at all to very much) for the extent to which they reflect the participant's responses to sadness. All items are preceded by the frame sentence "When I feel sad, down, or blue ...". Sample items are "...I repeatedly think about what might be the meaning of my sad feelings", "...I have difficulty getting myself to stop thinking about how sad I am", “...I repeatedly try to figure out, by doing a lot of thinking, what might be the causes of my sadness". The LARSS is an adapted and extended version of the Rumination 
on Sadness Scale (RSS; Conway, Csank, Holm, \& Blake, 2000) with good validity and reliability (Raes, Hermans, Williams, Bijttebier, \& Eelen, 2007).

\subsubsection{Stress Anxiety Depression version of the Means-Ends Problem Solving task} (SAD-MEPS; Hermans, Ruys, Vuerstaeck, Van Daele, \& Raes, 2007)

The original MEPS (Platt \& Spivack, 1975) assesses social problem-solving skills. It consists of a series of short stories or interpersonal problem situations faced by a hypothetical protagonist. Each story starts with the protagonist facing a specific problem, which is immediately followed by a successful ending. Participants are asked to provide the middle part of each story by describing strategies or means for solving the particular problem. We used an adapted format (Hermans et al., 2007), consisting of three scenarios: a depression-related, a stress-related, and an anxiety-related story. Two parallel sets were employed. According to the original manual (Platt \& Spivack, 1975; Spivack, Shure, \& Platt, 1981), stories were scored for number of relevant means (i.e. discrete sequenced steps that enable the protagonist to get closer to the stated goal). Following Marx, Williams, and Claridge (1992), stories were also scored for their effectiveness on a 7-point scale (not at all effective to extremely effective). Total scores result from summing scores across all three stories divided by three.

\subsubsection{Beck Hopelessness Scale (BHS; Beck \& Steer, 1988; Beck, Weissman, Lester, \&} Trexler, 1974)

The BHS is a self-report scale measuring negative attitudes about the future. It consists of 20 true-false statements. Total scores range between 0 and 20. Good reliability and validity is reported (Beck \& Steer, 1988; Beck et al., 1974).

\subsubsection{Acceptance and Action Questionnaire (AAQ-II; Bond, 2006)}

The AAQ-II measures the extent to which respondents engage in efforts to avoid, escape, or terminate (negative) internal or private experiences, such as bodily sensations, cognitions, and emotions (i.e. experiential avoidance). The AAQ-II consists of 10 items. Items are scored on a 7-point scale, ranging from 1 (never) to 7 (always). Total scores vary from 10 to 70 . Sample items are "My painful experiences and memories make it difficult for me to live a life that I would value", and "It's OK if I remember something unpleasant" (reversed item). The Dutch version by the 'ACTintervisie groep (2006)' was used.

\subsection{Procedure}

\subsubsection{General procedural aspects}

First, we presented the study to all team members of the two settings involved in the study: the psychiatric ward of the general hospital KLINA (Brasschaat, Belgium), and the 'FASE B' unit at the psychiatric hospital Sint-Norbertushuis (Duffel, Belgium). ${ }^{1}$ The team's psychologist then informed patients experiencing depressive symptomatology about the study. Next, those volunteering to participate were invited by the primary investigator (FR). Following written informed consent, they received a first set of questionnaires (pre-test). Later that week, the first session of the training was scheduled at which participants returned the completed questionnaire booklet. The next three sessions were delivered on a weekly basis following the first

\footnotetext{
${ }^{1}$ We thank Kris Van den Broeck, Lieve Gustin, and Jean-Marie Martens (KLINA), and Sieglinde Meganck and Bart Janssen (Sint-Norbertushuis) for their assistance in the conduct of this study.
} 
session. After the fourth and final session, participants again received the same set of questionnaires $^{2}$ which they returned to the primary investigator later that week.

\subsubsection{The training program: MEmory Specificity Training (MEST)}

The MEST program consists of four 1-h sessions, offered in groups of about three to eight participants for 4 consecutive weeks. The sessions are led by a single trainer (clinical psychologist). The general overarching aim of the complete program is to enhance the specificity with which participants retrieve personal events from their autobiographical memory.

Session 1 mainly consists of psychoeducation about memory functioning in relation to depression. Topics covered are (a) memory difficulties due to impaired concentration, (b) mood congruent encoding and retrieval, and (c) reduced autobiographical memory specificity. It is explained that reduced specificity does not tend to improve when people recover from their depression, and that it represents a latent vulnerability factor for depression. It is further explained what specific vs. overgeneral memories are (using personal examples from the trainer as well as other examples). Participants are then asked to recall a specific memory for a neutral ('bike') and a positive cue ('happy') and write these down in their personal workbook. They are prompted to recall as much details as possible (to further promote specificity). Based on, for example the work of Watkins and Philippot (e.g., Moberly \& Watkins, 2006; Neumann \& Philippot, 2007; Watkins \& Moulds, 2005), special attention is paid to spatio-temporal and contextual details, and sensory-perceptual details for the memories. Participants' responses are then discussed in group. At the end of the session, homework exercises for the next week are explained. For 10 cues (positive and neutral ones) participants need to generate a specific memory. They are also instructed to write down a 'specific memory of the day' every evening of the coming week.

Session 2 starts with a brief summary of Session 1. Next, the homework exercises are discussed in group. For the remaining of this second session, participants recall two specific memories for each of four cues (two positive and two neutral). Again, participants are motivated to recall as much (spatio-temporal, contextual, and sensory perceptual) details as possible. By asking participants to recall two different specific memories for the same cue, we aim to further promote the reduction of overgeneralization. Furthermore, participants are prompted to recall two memories that are quite different from one another, and they are asked to focus on, and pay close attention to those memory aspects or elements that made each memory specific and unique (as compared to the other memory for the same cue). By doing so, we want participants to abandon their focus on prototypical and generic elements of memories, which typically facilitate a tendency to overgeneralize (see e.g., Neumann \& Philippot, 2007). At the end of Session 2, the homework exercises for the coming week are explained. For 10 cues (positive and neutral ones) participants need to generate two different specific memories. They are also instructed to write down two different 'specific memories of the day' every evening of the coming week.

Session 3 is very similar to Session 2 in terms of the sort of exercises that participants need to do (i.e. two different and unique specific memories for one and the same cue). In Session 3, however, participants also need to work with more negative cues. As such, they are instructed to recall two specific memories for negative cues (clumsy, stressed, and sad). Following each negative cue, they are requested to do the same for the positive 'counterpart' cues (skilful, relaxed,

\footnotetext{
${ }^{2}$ The two AMT versions and two SAD-MEPS versions were administered in counterbalanced order across the two test moments (pre- and post-intervention).
} 
and happy). Besides promoting specificity of memory retrieval, by using positive and negative cues of a similar theme (clumsy and skilful, stressed and relaxed, sad and happy), we aim to reduce participants' tendency to overgeneralize (e.g., "I'm a clumsy person", "I'm always stressed", "I cannot relax", "I'm sad all the time", etc.). The homework assignment is similar to the homework exercises following Session 3, with the exception that now negative cues are provided as well.

In Session 4 participants are offered some further exercises using negative and ('counterpart') positive cues. It is also explained that overgeneral thinking can be brought 'on line' by a single experience (e.g., "Last Wednesday when my family came over, I ruined dinner", "Whenever I cook, things go wrong", "Whatever I do, things go wrong", "I'm a complete failure"). Several of such examples are discussed in order to promote participants' metacognitive awareness to know and notice when they are starting to shift to more general retrieval or unspecific thinking. Finally, a brief summary of the whole program is offered, and participants are invited to evaluate the course and to share their personal experiences with the training with the other group members and the trainer.

\section{Results}

\subsection{Check on parallel versions and normality tests}

$t$-Tests showed that the proportion of specific memories retrieved did not differ for both AMT versions, neither at $T_{1}$ (pre-intervention), nor at $T_{2}$ (post-intervention), both $p \mathrm{~s}>0.80$. Likewise, $t$-tests showed that both SAD-MEPS versions on both testing occasions did not lead to significantly different scores for the number of means or for the overall effectiveness of solutions generated, all $p s>0.33$. All this indicates that the different versions used for the AMT and SAD-MEPS can indeed be regarded as parallel versions.

Kolmogorov-Smirnov and Shapiro-Wilk tests for all variables of interest at both time points (pre- and post-intervention) were non-significant (all $p \mathrm{~s}>0.05$ ) suggesting that there were no significant deviations from normality, thereby allowing parametric analyses.

\subsection{Changes in memory specificity from pre- to post-intervention}

A repeated measures ANOVA on the proportion of specific memories on the AMT with time (pre- and post-intervention) as a within-subject factor, showed that memory specificity significantly increased from pre- to post-intervention, $F(1,9)=25.85, p<0.001$ (Partial EtaSquared, $\left.\eta_{\mathrm{p}}^{2},=0.74\right)$.

To check whether a decrease in depressive symptoms accounted for this increase in memory specificity, the repeated measures ANOVA was rerun, using change in BDI-II scores as a covariate. Change in BDI-II scores from pre- to post-intervention was assessed by means of standardized residual change scores. Residual change scores were computed by regressing post-intervention BDI-II scores on to pre-intervention BDI-II scores. The residuals indicate the difference between the actual post-intervention BDI-II score and the predicted postintervention BDI-II score. These residual change scores were then standardized. The advantage of using standardized residual change scores is that they control for individual differences in preintervention scores, that is, they represent the change in BDI-II level that is not expected on the basis of the pre-intervention level alone. Changes in memory specificity remained significant when controlling for BDI-II change scores, $F(1,8)=27.82, p<0.001$. This indicates that 
changes in depressive symptoms (e.g., symptom improvement) do not explain the changes (e.g., improvement) in memory specificity.

To examine whether improvement in memory specificity is not restricted to the standard AMT measure, but also generalizes to an alternative measure for memory specificity, a repeated ANOVA was calculated on the proportion of specific completions on the SCEPT measure with time (pre- and post-intervention) as a within-subject factor. This analysis too, showed a significant increase in memory specificity, $F(1,9)=5.99, p<0.05$. When corrected for changes in BDI-II scores (as a covariate), the change in memory specificity as measured with the SCEPT remained significant, $F(1,8)=6.43, p<0.05$, indicating that changes in depressive symptoms do not explain the increase in memory specificity on the SCEPT.

\subsection{Changes in rumination, problem-solving skills, hopelessness and experiential avoidance and its relations to changes in memory specificity}

A repeated measures ANOVA with time (pre- and post-intervention) as a within-subject factor was conducted for each of the five other variables of interest (see Table 1). These analyses showed a significant decrease in rumination (LARSS), $F(1,8)=8.08, p<0.05$, and a significant decrease in feelings of hopelessness, $F(1,9)=8.71, p<0.05$. As for problem-solving skills, the analyses showed a non-significant decrease for the number of means on the SAD-MEPS, $F(1$, $8)=2.55, p=0.15$, and a marginally significant increase in the overall effectiveness of solutions generated on the SAD-MEPS, $F(1,8)=4.00, p=0.08$. Scores on the AAQ-II decreased from pre- to post-intervention, but this decrease in experiential avoidance was not significant, $F(1,9)=1.80, p=0.21$.

Next, we calculated standardized residual change scores for each of the above variables, to examine whether, as predicted, changes in memory specificity over the course of the memory training correlate with changes in those five variables. As can be seen from Table 2, changes in memory specificity were negatively correlated with changes in rumination and experiential avoidance. Changes in memory specificity were significantly positively correlated with changes in overall effectiveness of solutions on the SAD-MEPS, and marginally significant with

Table 1

Means and standard deviations for all relevant variables at pre $\left(T_{1}\right)$ and post $\left(T_{2}\right)$

\begin{tabular}{lrrrr}
\hline Variable & \multicolumn{1}{c}{$T_{1}$} & & \multicolumn{2}{c}{$T_{2}$} \\
\cline { 2 - 3 } & \multicolumn{1}{c}{$M$} & SD & \multicolumn{1}{c}{ SD } \\
\hline AMT-pS & 0.44 & 0.28 & 0.72 & 0.24 \\
SCEPT-pS & 0.32 & 0.16 & 0.48 & 0.14 \\
BDI-II & 25.30 & 10.70 & 15.80 & 13.11 \\
LARSS & 47.78 & 16.83 & 41.67 & 12.77 \\
SAD-MEPS & & & 3.04 & 1.29 \\
$\quad$ Means & 3.41 & 1.42 & 5.04 & 1.16 \\
$\quad$ Effectiveness & 4.59 & 1.49 & 8.60 & 5.87 \\
BHS & 11.50 & 4.53 & 42.60 & 12.14 \\
AAQ-II & 45.30 & 12.68 & & \\
\hline
\end{tabular}

Note. AMT-pS = Autobiographical Memory Test proportion Specific memories; SCEPT-pS = Sentence Completion for Events from the Past Test proportion Specific completions; BDI-II = Beck Depression Inventory II; LARSS = Leuven Adaptation of the Rumination on Sadness Scale; SAD-MEPS = Stress Anxiety and Depression Means End ProblemSolving Task; BHS = Beck Hopelessness Scale; AAQ-II = Acceptance and Action Questionnaire II. 
Table 2

Correlations and partial correlations (corrected for changes in depressive symptoms; BDI-II) between standardized residual change scores for memory specificity (AMT) and standardized residual change scores for the other variables of interest

\begin{tabular}{|c|c|c|c|c|}
\hline & \multicolumn{4}{|c|}{$\Delta$ AMT-pS } \\
\hline & $r$ & $p$ & $\begin{array}{l}\text { Partial } r \\
(\Delta \text { BDI-II partialled })\end{array}$ & $p$ \\
\hline$\Delta \mathrm{LARSS}$ & -0.75 & 0.02 & -0.79 & 0.02 \\
\hline \multicolumn{5}{|l|}{$\Delta$ SAD-MEPS } \\
\hline$\Delta$ Means & 0.65 & 0.06 & 0.67 & 0.07 \\
\hline$\Delta$ Effectiveness & 0.74 & 0.02 & 0.75 & 0.03 \\
\hline$\Delta \mathrm{BHS}$ & -0.43 & 0.22 & -0.53 & 0.14 \\
\hline$\Delta$ AAQ-II & -0.64 & 0.04 & -0.66 & 0.05 \\
\hline
\end{tabular}

Note. $\Delta=$ (standardized residual) change (score); AMT-pS = Autobiographical Memory Test proportion Specific memories; BDI-II = Beck Depression Inventory II; LARSS = Leuven Adaptation of the Rumination on Sadness Scale; SAD-MEPS = Stress Anxiety and Depression Means End Problem-Solving Task; BHS = Beck Hopelessness Scale; AAQ-II = Acceptance and Action Questionnaire II.

changes in the number of means in the solutions that were generated in response to the SADMEPS stories. Importantly, we also computed partial correlations between changes in memory specificity and changes on those five variables, controlling for changes in depressive symptomatology (BDI-II change scores). We did this to verify to what extent the observed and predicted relationships would still remain, once BDI-II change scores are controlled for (as changes in depressive symptoms may act as a third variable). These partial correlations were hardly any different from the zero order correlations (see also Table 2), with the exception that the significance of the correlation between memory specificity change scores and change scores for experiential avoidance was now only marginally significant $(p<0.06)$. As such we can conclude that the predicted associations between changes in memory specificity and changes in the other variable of interest are not simply due to changes in depressive symptoms. ${ }^{3}$

\section{Discussion}

The current study was a preliminary evaluation of a newly developed group-based intervention program for patients with depressive symptomatology to reduce overgenerality of autobiographical memory specificity, a known depressogenic cognitive process. The MEmory Specificity Training program (MEST) consists of four 1-h sessions offered for 4 consecutive weeks. Its main purpose is to directly target that depressogenic process by increasing the specificity with which participants retrieve personal memories. The primary aim of the current study was to examine whether this program leads to an increase in specificity of autobiographical memories. Results showed that participants' retrieval style indeed became significantly more

\footnotetext{
${ }^{3}$ Given the (marginally) significant relationships between changes in memory specificity and changes in scores on the LARSS, AAQ-II, and SAD-MEPS, we reran the repeated measures ANOVA on the proportion of specific memories on the AMT with time (pre- and post-intervention) as a within-subject factor, not only with BDI-II change scores as a covariate, but with change scores for the LARSS, AAQ-II, and SAD-MEPS as covariates as well. Changes in memory specificity remained significant when controlling for change scores on the BDI-II, LARSS, AAQ-II, and SAD-MEPS, $F(1,2)=72.44, p<0.05$. This indicates that changes in any of the other variables do not explain the changes (e.g., improvement) in memory specificity.
} 
specific following the MEST program. Moreover, this effect was not due to a reduction in depressive complaints. Especially against the background of previous work indicating that memory specificity does not tend to increase when patients recover from depression following treatment as usual, our results suggest that the MEST program was successful at reducing this known vulnerability factor of reduced memory specificity.

Secondly, our results showed, as predicted, that the observed improvements in memory specificity are accompanied by improvements in variables that are assumed to mediate the impact of memory specificity on the course of depression. Participants who increased the most in the generation of specific memories improved most on such variables (greater relative decreases in rumination and in experiential avoidance, and greater relative increases in problem-solving skills). These findings remained when controlled for changes in depressive symptomatology, indicating that the associations between changes in memory specificity and changes in these other variables are not simply due to changes in depressive symptoms. These observations, thus, further underscore the validity of our MEST program, and provide further evidence for the associations, as previously hypothesized in the literature, between memory specificity on the one hand, and rumination, cognitive avoidance, and problem-solving skills on the other hand.

Importantly, with respect to the study's third aim, results also indicated that this effect generalized to a procedure different than the standard AMT cue-words. When participants were asked to complete sentence stems that probe for past events, they completed these sentence beginnings with more specific event material after the training program as compared to the start of the study. Previous studies evaluating the course of memory specificity over time have only relied on the cue-word procedure. Our study shows that the positive effects of the MEST program are not restricted to this cue-word task.

Patients that completed the program all evaluated the training sessions very positively. Some particularly appreciated the fact that their memory complaints were finally given some attention. Others noted how they now noticed much more details of things that were going on around them. We assume that this likely increases the specificity with which new memories are being encoded, which in turn can aid specificity of later retrieval. Some participants also stressed that they now somehow seem to hold a more balanced and diversified view on current and past issues.

Several design limitations of this preliminary study should be recognized. All point to interesting potential directions for future research. Especially given the fact that this is a preliminary study, putative future research directions need to be considered.

One limitation of the current study is its small sample size. As such, there is a clear case for repeating the study in a larger sample, to confirm the pattern of results reported here. We also note that all participants in our current study were women, hence limiting the generalizability of the present findings to men. Further work, thus, will need to examine whether the present results also generalize to men.

Second, no follow-up testing was included in this preliminary study. Hence, the present study should be extended in future studies by including a follow-up period to examine to what extent the memory specificity training leads to a decrease in depressive symptoms and/or a reduction in risk for relapse in the longer run. The fact that we observed an association between the relative increase in memory specificity and improvements in hypothesized mediators of the relationship between memory specificity and depression is particularly promising in this respect.

Another, third limitation of the current design involves the absence of a control group. As such, we cannot causally attribute the observed improvements in terms of memory specificity to our training. It is important to note, however, that previous research has shown that memory 
specificity does not improve when patients receive treatment as usual (see our review in Section 1). Even when patients recover or start to show a decrease in depressive symptomatology, their level of memory specificity does not typically tend to increase. We are quite confident in concluding, therefore, that the observed and marked improvements in memory specificity were due to our targeted intervention. Nevertheless of course, further research will need to include a control group (a waiting list control group, or an attentional placebo control group). Additionally it would also be interesting to examine the longer-term effects of our program in recovered (instead of currently) depressed patients in terms of relapse prevention, as compared to a control group.

Fourth, this study had a relatively large drop-out rate $(n=7)$. The major cause of drop-out $(n=4)$, however, was discharge from the hospital prior to the end of the 4-week training period. In current research we now try to prevent this by explicitly inviting participants to attend the training sessions even after they have been discharged from the hospital.

Finally, results from this study relied on paper-pencil measures only (most often direct selfreport instruments). Further research should therefore also include other instruments, such as clinician rated scales and/or indirect, or so-called implicit measures. We must note, however, that the SCEPT is not a simple direct self-report measure, as respondents do not know what this task precisely measures or focuses on. Also the SAD-MEPS, although being a self-report scale, is less likely to be vulnerable to, for example, impression management.

In conclusion, the present study provides preliminary evidence that our MEST program is able to reduce a known vulnerability factor for depression, i.e. unspecific retrieval of memories. This positive effect was not due to a reduction in depressive symptoms, and was found to generalize to a procedure different than the standard cue-word task. Also, amelioration in memory specificity seems to have led to amelioration in associated variables such as rumination and problem-solving skills. In terms of cost-benefit issues, we also believe that the MEST's group-format has some advantages over individually administered interventions (see, for example, Serrano et al., 2004). These results, which need to be regarded as strictly provisional until replicated within designs using larger samples with longer follow-ups, suggest that the MEST group-program offers a potential and promising intervention to tackle a core cognitive process involved in depression and depressive vulnerability.

\section{References}

ACTintervisie groep. (2006). De Nederlandstalige versie van AAQ-II. [The Dutch version of the AAQ-II]. Unpublished manuscript.

American Psychiatric Association. (1994). Diagnostic and statistical manual of mental disorders (4th ed.). Washington, DC: American Psychiatric Association.

Barlow, D. H. (2004). Psychological treatments. American Psychologist, 59, 869-878.

Beck, A. T., \& Steer, R. A. (1988). Manual for the Beck Hopelessness Scale. San Antonio, TX: The Psychological Corporation.

Beck, A. T., Steer, R. A., \& Brown, G. K. (1996). Beck Depression Inventory, (2nd ed.). San Antonio, TX: The Psychological Corporation.

Beck, A. T., Weissman, A., Lester, D., \& Trexler, L. (1974). The measurement of pessimism: the Hopelessness Scale. Journal of Consulting and Clinical Psychology, 42, 861-865.

Bond, F. (2006). The acceptance and action questionnaire, second version. Unpublished manuscript.

Brittlebank, A. D., Scott, J., Williams, J. M. G., \& Ferrier, I. N. (1993). Autobiographical memory in depression: state or trait marker? British Journal of Psychiatry, 162, 118-121.

Bryant, R. A., Sutherland, K., \& Guthrie, R. M. (2007). Impaired specific autobiographical memory as a risk factor for posttraumatic stress after trauma. Journal of Abnormal Psychology, 116, 837-841. 
Conway, M., Csank, P. A. R., Holm, S. L., \& Blake, C. K. (2000). On assessing individual differences in rumination on sadness. Journal of Personality Assessment, 75, 404-425.

de Decker, A. (2001). The specificity of the autobiographical memory retrieval style in adolescents with a history of trauma. Unpublished doctoral dissertation, University of Leuven, Belgium.

Evans, J., Williams, J. M. G., O’Loughlin, S., \& Howells, K. (1992). Autobiographical memory and problem-solving strategies of parasuicide patients. Psychological Medicine, 22, 399-405.

Gibbs, B. R., \& Rude, S. S. (2004). Overgeneral autobiographical memory as depression vulnerability. Cognitive Therapy and Research, 28, 511-526.

Goddard, L., Dritschel, B., \& Burton, A. (1996). Role of autobiographical memory in social problem solving and depression. Journal of Abnormal Psychology, 105, 609-616.

Goddard, L., Dritschel, B., \& Burton, A. (1997). Social problem solving and autobiographical memory in non-clinical depression. British Journal of Clinical Psychology, 36, 449-451.

Golden, A. M., Dalgleish, T., \& Mackintosh, B. (2007). Levels of specificity of autobiographical memories and of biographical memories of the deceased in bereaved individuals with and without complicated grief. Journal of Abnormal Psychology, 116, 786-795.

Hayes, S. C., Wilson, K. G., Gifford, E. V., Follette, V. M., \& Strosahl, K. (1996). Experiential avoidance and behavioral disorders: a functional dimensional approach to diagnosis and treatment. Journal of Consulting and Clinical Psychology, 64, 1152-1168.

Hermans, D., Raes, F., \& Eelen, P. (2005). Mood and memory. A cognitive psychology perspective on maintenance of depressed mood and vulnerability for relapse. In J. Corveleyn, P. Luyten, \& S. J. Blatt (Eds.), The theory and treatment of depression: Towards a dynamic interactionism model (pp. 43-66). Leuven, Belgium/Mahwah, NJ: Leuven University Press/Lawrence Erlbaum Associates.

Hermans, D., Ruys, K., Vuerstaeck, S., Van Daele, T., \& Raes, F. (2007, November). Autobiographical memory specificity and the effects of a psycho-educational programme for stress and anxiety. In Paper presented at the 41 st Annual Convention of the Association for Behavioral and Cognitive Therapies (ABCT), Philadelphia, USA.

Hermans, D., Vandromme, H., Debeer, E., Raes, F., Demyttenaere, K., Brunfaut, E., et al. Overgeneral autobiographical memory predicts diagnostic status in depression. Behaviour Research and Therapy, in press.

Littrell, J. (1998). Is the reexperience of painful emotion therapeutic? Clinical Psychology Review, 18, 71-102.

McBride, C., Segal, Z., Kennedy, S., \& Gemar, M. (2007). Changes in autobiographical memory specificity following cognitive behavior therapy and pharmacotherapy for major depression. Psychopathology, 40, 147-152.

Mackinger, H. F., Loschin, G. G., \& Leibetseder, M. M. (2000). Prediction of postnatal affective changes by autobiographical memories. European Psychologist, 5, 52-61.

Mackinger, H. F., Pachinger, M. M., Leibetseder, M. M., \& Fartacek, R. R. (2000). Autobiographical memories in women remitted from major depression. Journal of Abnormal Psychology, 109, 331-334.

Marx, E. M., Williams, J. M. G., \& Claridge, G. C. (1992). Depression and social problem solving. Journal of Abnormal Psychology, 101, 78-86.

Moberly, N. J., \& Watkins, E. R. (2006). Processing mode influences the relationship between trait rumination and emotional vulnerability. Behavior Therapy, 37, 281-291.

Neumann, A., \& Philippot, P. (2007). Specifying what makes a personal memory unique enhances emotion regulation. Emotion, 7, 566-578.

Park, R. J., Goodyer, I. M., \& Teasdale, J. D. (2002). Categoric overgeneral autobiographical memory in adolescents with major depressive disorder. Psychological Medicine, 32, 267-276.

Peeters, F., Wessel, I., Merckelbach, H., \& Boon-Vermeeren, M. (2002). Autobiographical memory specificity and the course of major depressive disorder. Comprehensive Psychiatry, 43, 344-350.

Pennebaker, J. W., \& Seagal, J. D. (1999). Forming a story: the health benefits of narrative. Journal of Clinical Psychology, 55, 1243-1254.

Platt, J. J., \& Spivack, G. (1975). Manual for the Means-Ends Problem-Solving procedure (MEPS): A measure of interpersonal problem-solving skill. Philadelphia: Department of Mental Health Sciences, Hahnemann Medical College and Hospital.

Raes, F., Hermans, D., de Decker, A., Eelen, P., \& Williams, J. M. G. (2003). Autobiographical memory specificity and affect regulation: an experimental approach. Emotion, 3, 201-206.

Raes, F., Hermans, D., Williams, J. M. G., Beyers, W., Brunfaut, E., \& Eelen, P. (2006). Reduced autobiographical memory specificity and rumination in predicting the course of depression. Journal of Abnormal Psychology, 115, 699-704.

Raes, F., Hermans, D., Williams, J. M. G., Bijttebier, P., \& Eelen, P. (2007). A “triple W"-model of rumination on sadness: why am I feeling sad, what's the meaning of my sadness, and wish I could stop thinking about my sadness (but I can’t!). Cognitive Therapy and Research. doi:10.1007/s10608-007-9137-y. 
Raes, F., Hermans, D., Williams, J. M. G., Demyttenaere, K., Sabbe, B., \& Pieters, G., et al. (2005). Reduced specificity of autobiographical memories: a mediator between rumination and ineffective problem solving in major depression? Journal of Affective Disorders, 87, 331-335.

Raes, F., Hermans, D., Williams, J. M. G., \& Eelen, P. (2007). A sentence completion procedure as an alternative to the autobiographical memory test for assessing overgeneral memory in non-clinical populations. Memory, 15, $495-507$.

Raes, F., Hermans, D., Williams, J. M. G., Geypen, L., \& Eelen, P. (2006). The effect of overgeneral autobiographical memory retrieval on rumination. Psychologica Belgica, 46, 131-141.

Raes, F., Pousset, G., \& Hermans, D. (2004). Correlates of autobiographical memory specificity in a nonclinical student population. Unpublished manuscript.

Ramponi, C., Barnard, P. J., \& Nimmo-Smith, I. (2004). Recollection deficits in dysphoric mood: an effect of schematic models and executive mode? Memory, 12, 655-670.

Serrano, J. P., Latorre, J. M., Gatz, M., \& Montanes, J. (2004). Life review therapy using autobiographical retrieval practice for older adults with depressive symptomatology. Psychology and Aging, 19, 272-277.

Spivack, G., Shure, M. B., \& Platt, J. J. (1981). Means-Ends Problem Solving: Stimuli and scoring procedures supplement. Philadelphia: Department of Mental Health Sciences, Hahnemann Medical College \& Hospital.

Van der Does, A. J. W. (2002). Handleiding bij de Nederlandse bewerking van de BDI-II. [Manual of the Dutch version of the BDI-II]. San Antonio, TX/Lisse, the Netherlands: The Psychological Corporation/Swets Test Publishers.

Van der Does, A. J. W., Barnhofer, T., \& Williams, J. M. G. (2003). The Major Depression Questionnaire (MDQ). Available from: www.dousa.nl/publications.

Van Minnen, A., Wessel, I., Verhaak, C., \& Smeenk, J. (2005). The relationship between autobiographical memory specificity and depressed mood following a stressful life event: a prospective study. British Journal of Clinical Psychology, 44, 405-415.

Watkins, E. R., \& Moulds, M. (2005). Distinct modes of ruminative self-focus: impact of abstract versus concrete rumination on problem solving in depression. Emotion, 5, 319-328.

Watkins, E., \& Teasdale, J. D. (2001). Rumination and overgeneral memory in depression: effects of self-focus and analytic thinking. Journal of Abnormal Psychology, 110, 353-357.

Watkins, E., \& Teasdale, J. D. (2004). Adaptive and maladaptive self-focus in depression. Journal of Affective Disorders, $82,1-8$.

Watkins, E., Teasdale, J. D., \& Williams, R. M. (2000). Decentring and distraction reduce overgeneral autobiographical memory in depression. Psychological Medicine, 30, 911-920.

Williams, J. M. G. (1996). Depression and the specificity of autobiographical memory. In D. C. Rubin (Ed.), Remembering our past: Studies in autobiographical memory (pp. 244-267). Cambridge, England: Cambridge University Press.

Williams, J. M. G. (2004). Experimental cognitive psychology and clinical practice: autobiographical memory as a paradigm case. In J. Yiend (Ed.), Cognition, emotion and psychopathology (pp. 251-269). Cambridge, England: Cambridge University Press.

Williams, J. M. G., Barnhofer, T., Crane, C., \& Beck, A. T. (2005). Problem solving deteriorates following mood challenge in formerly depressed patients with a history of suicidal ideation. Journal of Abnormal Psychology, $114,421-431$.

Williams, J. M. G., Barnhofer, T., Crane, C., Hermans, D., Raes, F., \& Watkins, E., et al. (2007). Autobiographical memory specificity and emotional disorder. Psychological Bulletin, 133, 122-148.

Williams, J. M. G., \& Broadbent, K. (1986). Autobiographical memory in suicide attempters. Journal of Abnormal Psychology, 95, 144-149.

Williams, J. M. G., Chan, S., Crane, C., Barnhofer, T., Eade, J., \& Healy, H. (2006). Retrieval of autobiographical memories: the mechanisms and consequences of truncated search. Cognition \& Emotion, 20, 351-382.

Williams, J. M. G., \& Dritschel, B. H. (1988). Emotional disturbance and the specificity of autobiographical memory. Cognition \& Emotion, 2, 221-234.

Williams, J. M. G., Ellis, N. C., Tyers, C., Healy, H., Rose, G., \& MacLeod, A. K. (1996). Specificity of autobiographical memory and imageability of the future. Memory and Cognition, 24, 116-125.

Williams, J. M. G., Teasdale, J. D., Segal, Z. V., \& Soulsby, J. (2000). Mindfulness-based cognitive therapy reduces overgeneral autobiographical memory in formerly depressed patients. Journal of Abnormal Psychology, 109, 150-155.

Williams, J. M. G., Van der Does, A. J. W., Barnhofer, T., Crane, C., \& Segal, Z. V. (2008). Cognitive reactivity, suicidal ideation and future fluency: investigating a differential activation theory of suicidality. Cognitive Therapy and Research, 32, 83-104. 